\title{
Interactive comment on "In-flight calibration and monitoring of the TROPOMI-SWIR module" by Tim A. van Kempen et al.
}

\section{Tim van Kempen}

t.a.van.kempen@sron.nl

Received and published: 17 September 2019

Comments appear to be empty. Was this the intention?

Interactive comment on Atmos. Meas. Tech. Discuss., doi:10.5194/amt-2019-270, 2019. 